\title{
Effects of hypnosis on the relative parasympathetic tone measured by ANI (Analgesia/Nociception Index) in healthy volunteers
}

Boselli E.1 , Musellec H. ${ }^{2}$, Martin L. ${ }^{2}$, Bernard F. ${ }^{2}$, Virot C. ${ }^{3}$, Émergences instructors

${ }^{1}$ University Lyon I Claude Bernard, Lyon, France ; ${ }^{2}$ Centre hospitalier privé Saint-Grégoire, SaintGrégoire, France ; ${ }^{3 E ́ m e r g e n c e s, ~ I n s t i t u t ~ d e ~ f o r m a t i o n ~ d e ~ r e c h e r c h e ~ e n ~ h y p n o s e ~ e t ~}$ communication thérapeutique, Rennes, France

Background and Goal of Study: The efficacy of hypnosis has been demonstrated to reduce the patients pain or anxiety and hypnosis is currently gaining interest in particular in the operating room [1]. Hypnosis induces reduced sympathetic activity and increased parasympathetic activity [2]. The Analgesia/Nociception Index (ANI) is a 0-100 index reflecting the relative parasympathetic tone [3]. We assessed the effects of hypnosis on ANI in healthy volunteers.

Materials and methods: After IRB approval (CPP Sud-Est IV $\mathrm{n}^{\circ}$ L16-89) and written informed consent, subjects participating to the 6th "Hypnosis and Pain" congress in Saint Malo, France (May 2016) were recruited. Exclusion criteria were history of arrhythmia or pace-maker. After comfortable installation of the subject in the sitting position and collection of accompanying theme elements from a pleasant memory such a nice journey (TO), the hypnotherapist induced the hypnotic trance by asking the subject to take a deep breath (T1). The theme was then returned to the subject with suggestions of comfort during 5 to $10 \mathrm{~min}$. Once the subject validated his comfort by a signaling such as putting a thumb up or nodding the head (T2), he was then progressively brought back to full awareness (T3). The ANI was recorded at each time point using the ANI Monitor ${ }^{\circledR}$ (MDoloris Medical Systems, Lille, France), as well as heart rate (HR) and respiratory rate (RR) counted on $15 \mathrm{~s}$. The ANI, HR and RR were compared at each time point using ANOVA with $p<0.05$ considered as statistically significant.

Results and discussion: 40 subjects ( 31 women, 9 men) were included. The ANI was significantly greater at $\mathrm{T} 2$ than at the other time points (Fig. 1). The HR did not vary significantly from T0 to T3 (Fig. 2). The RR was significantly lower at T1 and $\mathrm{T} 2$ than at the other time points (Fig. 3). A screenshot of variations of $\mathrm{ANI}$ between $\mathrm{T} 1$ and $\mathrm{T} 2$ appears in Fig. 4. Conclusion(s): Hypnosis induces increased relative parasympathetic tone continuously monitored using ANI and decreased RR with no variation of HR in healthy volunteers.

\section{References:}

[1] Clin Psychol Rev 2013;33:623-36

[2] Neuropsychobiology 2009;60:104-12

[3] Prat Anesth Réanim 2015;19:78-86
Euroanaesthesia

A_805_0064_00269

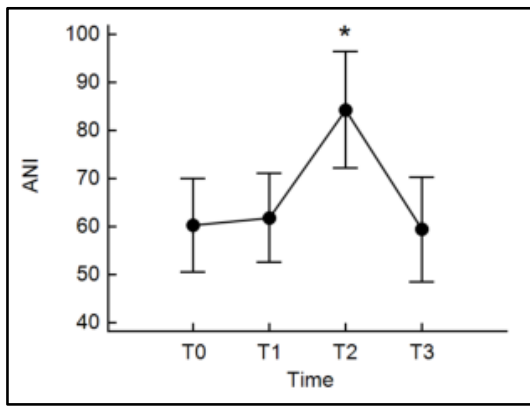

Figure 1

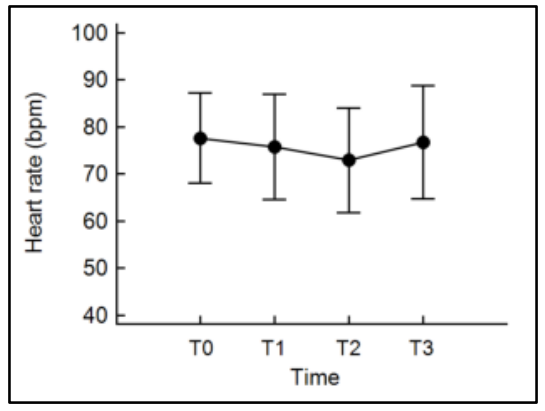

Figure 2

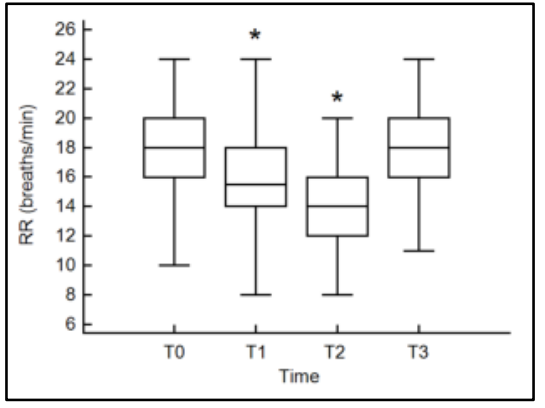

Figure 3

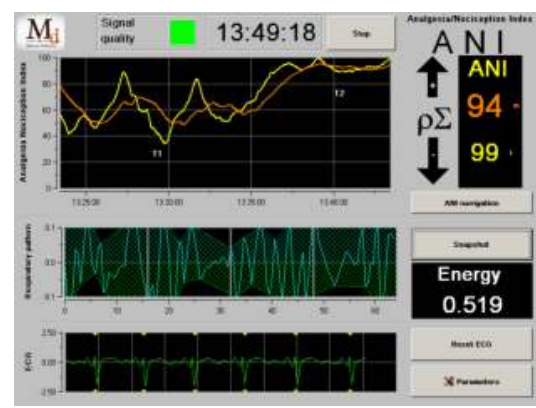

Figure 4 